\title{
Meta
}

Journal des traducteurs

Translators' Journal

Serge LUSIGNAN (1986) : Parler vulgairement. Les intellectuels

et la langue française aux XIIIe et XIVe siècles, Paris, Librairie académique Vrin et Montréal, Presses de l'Université de Montréal (coll. Études médiévales)

\section{Jérôme Daviault}

Volume 35, numéro 2, juin 1990

URI : https://id.erudit.org/iderudit/002488ar

DOI : https://doi.org/10.7202/002488ar

Aller au sommaire du numéro

Éditeur(s)

Les Presses de l'Université de Montréal

ISSN

0026-0452 (imprimé)

1492-1421 (numérique)

Découvrir la revue

Citer ce compte rendu

Daviault, J. (1990). Compte rendu de [Serge LUSIGNAN (1986) : Parler vulgairement. Les intellectuels et la langue française aux XIIIe et XIVe siècles,

Paris, Librairie académique Vrin et Montréal, Presses de l'Université de

Montréal (coll. Études médiévales)]. Meta, 35(2), 450-451.

https://doi.org/10.7202/002488ar d'utilisation que vous pouvez consulter en ligne. 
Serge LUSIGNAN (1986): Parler vulgairement. Les intellectuels et la langue française aux XIII et XIV siècles, Paris, Librairie académique Vrin et Montréal, Presses de l'Université de Montréal (coll. Études médiévales).

L'auteur décrit les premiers signes de l'accès du français au statut de langue enseignée et normalisée, capable d'exprimer la pensée abstraite.

Le XIII ${ }^{e}$ siècle, qui marque l'apogée du Moyen Âge, établit une dichotomie très nette entre la langue vulgaire et la langue des clercs. La première s'apprend exclusivement auprès de la mère; la seconde, exclusivement à l'école. Différence des 
apprentissages et aussi différence des rôles: le latin a le monopole de la science. Seule langue normalisée (on l'appelle parfois la «grammaire»), le latin apparaît comme moyen d'échange indispensable pour la Chrétienté occidentale.

La situation commence à évoluer au XIVe siècle sous l'impulsion des cours d'Angleterre et de France. Pour des motifs politiques, les rois d'Angleterre désirent pallier le déclin de l'anglo-normand par l'enseignement du français, qui s'aligne sur l'usage de Paris. C'est pourquoi la première grammaire française (le Donait françoys de John Barton) est rédigée en Angleterre vers 1400.

La même nécessité ne se manifeste pas de l'autre côté de la Manche. C'est par le biais de la traduction que s'effectueront la promotion du français et la prise de conscience de ses particularités. En effet, le pouvoir royal (particulièrement sous le règne de Charles $\mathrm{V}$, de 1365 à 1380) commandera de nombreuses «translations» des classiques antiques, de la Vulgate et de la littérature patristique.

Les traducteurs royaux se sont livrés à une réflexion sur leur activité et sur la nature des langues avec lesquelles ils se colletaient. Ils ont pris conscience de l'écart qui sépare le latin de Virgile de celui de Thomas d'Aquin; le style «grief et suspensif» de Tacite et de Sénèque les laisse parfois perplexes. C'est pourquoi ils préconisent la traduction phrase par phrase plutôt que mot par mot. En outre, ils perçoivent les lacunes lexicales et stylistiques du français. Pour combler les premières, ils ont réalisé un véritable travail de terminologie : création de multiples néologismes, rédaction de lexiques, souci de normalisation. Toutefois, ils ne se sont guère sentis aptes à surmonter les déficiences stylistiques. Selon Lusignan, c'est qu'ils percevaient encore le français comme une langue essentiellement orale.

Nicole Oresme se détache de ce groupe de pionniers, à cause de l'ampleur de son œuvre et de la philosophie qu'elle lui inspire. Conscient lui aussi de l'imperfection de son travail, il entrevoit néanmoins que «cette noble science (pourra) au temps à venir estre baillée par autres en françois plus clerement et plus complectement». Il est donc le premier à entrevoir avec netteté la perfectibilité du français, qu'il relie au thème de la translatio studii: le flambeau de la connaissance, transmis jadis de la Grèce à Rome, est passé à Paris; par conséquent, le français accédera un jour à la parité avec le grec et le latin. Le plus grand traducteur du XIVe siècle a été un précurseur de la Renaissance, de Du Bellay et de Montaigne.

JÉRÔME DAVIAULT 